\title{
The potential for patient-led COPD admission avoidance schemes
}

\section{To the Editors:}

Recent guidance on intermediate care for chronic obstructive pulmonary disease (COPD) highlights the invaluable role of "early assisted discharge" and "hospital at home" in improving patient care and reducing length of hospitalisation for exacerbations [1]. We would like to draw on our novel local experience to suggest a potentially useful addition to such services: namely, a largely patient-triggered "in-reach" service for selected COPD patients from the community.

Southampton has been identified as a COPD "hotspot" in the southern part of the UK [2]. Local COPD management is now largely coordinated through a multidisciplinary service called The Respiratory Centre (TRC) at Southampton General Hospital (Southampton). This service offers early assisted discharge, post-discharge reviews, follow-up for chronic management and urgent review of exacerbating COPD patients. Urgent review can be accessed directly by COPD patients known to TRC as well as general practitioners (GP). A specialist nurse, physiotherapist and respiratory consultant usually see patients within $24 \mathrm{~h}$, between 09:00-17:00 h, Monday to Friday. We recently reviewed the use and efficacy of this novel urgent referral service and present relevant findings below.

Our review focused on all COPD patients using the TRC urgent referral system in a 12-month period between September 1, 2004 and August 31, 2005. In total, 82 individuals used the facility during that period. Data were obtained from the local patient database.

Most patients who used the service "self-referred" (67\%), although some were referred by GP (21\%) or community respiratory team $(11 \%)$. There was a slight male predominance amongst users (59\%), who had a mean age of 70.2 yrs. It was possible to discharge most patients (94\%) after review, with escalation of therapy in $68 \%$ of cases. Community support was needed for $12 \%$ of discharged patients. Of the urgently referred patients, $6 \%$ were admitted following review. Amongst patients discharged after review, $11 \%$ were subsequently admitted during the "index exacerbation" (i.e. failed discharge). During the 12 months following initial review, $52 \%$ of subjects went on to have further urgent reviews, while $23 \%$ of subjects had a COPD-related hospitalisation during that period.

Patients were further categorised as having "mild", "moderate", "severe" and "very severe" COPD, using Global Initiative for Chronic Obstructive Lung Disease (GOLD) criteria (table 1) [3]. Most patients (79\%) had severe or very severe disease, with worse indices for lung function, body mass index, baseline therapy and mortality. Amongst those needing admission post review, most $(75 \%)$ were severe or very severe. Subsequent urgent referrals (83\%) and hospitalisations (93\%) over the following year occurred mostly in severe or very severe patients. However, whilst $65 \%$ of the

\begin{tabular}{|c|c|c|c|c|}
\hline \multirow[t]{2}{*}{ TABLE 1} & \multirow[b]{2}{*}{ Mild } & \multirow[b]{2}{*}{ Moderate } & \multirow[b]{2}{*}{ Severe } & \multirow[b]{2}{*}{$\begin{array}{l}\text { Very } \\
\text { severe }\end{array}$} \\
\hline & & & & \\
\hline Subjects $n$ & 1 & 12 & 24 & 26 \\
\hline Age yrs & $70.0 \pm 0.0$ & $70.8 \pm 11.0$ & $72.4 \pm 11.8$ & $68.6 \pm 11.7$ \\
\hline Mean BMI & $22.0 \pm 0.0$ & $31.1 \pm 9.1$ & $26.9 \pm 6.1$ & $23.9 \pm 5.3$ \\
\hline Mean FEV 1 \% pred & $96.0 \pm 0.0$ & $56.6 \pm 8.2$ & $40.9 \pm 4.6$ & $23.5 \pm 4.4$ \\
\hline Admitted into hospital & $0(0)$ & $1(8.3)$ & 2 (8.3) & $1(3.8)$ \\
\hline $\begin{array}{l}\text { Received new acute } \\
\text { treatment }\end{array}$ & $0(0)$ & $4(33.3)$ & $17(70.8)$ & $21(80.8)$ \\
\hline $\begin{array}{l}\text { Hospital admissions in } \\
\text { following } 12 \text { months }\end{array}$ & $0(0)$ & $1(8.3)$ & $5(20.8)$ & $9(34.6)$ \\
\hline $\begin{array}{l}\text { Urgent referral within } \\
\text { following } 12 \text { months }\end{array}$ & $1(100)$ & $5(41.7)$ & $12(50.0)$ & $17(65.4)$ \\
\hline $\begin{array}{l}\text { TRC attendance in } \\
\text { following } 12 \text { months }\end{array}$ & $3.0 \pm 0.0$ & $3.3 \pm 2.6$ & $4.0 \pm 3.1$ & $5.4 \pm 3.2$ \\
\hline $\begin{array}{l}\text { Death within following } \\
12 \text { months }\end{array}$ & $0(0)$ & $3(25)$ & $1(4.2)$ & $7(26.9)$ \\
\hline
\end{tabular}

Data are presented as mean \pm SD or $n(\%)$. A total of $63(77 \%)$ patients had "stable" lung function (within the previous 12 months of index referral) and could thus be categorised according to severity. COPD severity was defined using forced expiratory volume in one second (FEV 1$) \%$ predicted, in the setting of $\mathrm{FEV}_{1} /$ forced vital capacity ratio $<70 \%$, as per the following Global Initiative for Chronic Obstructive Lung Disease (GOLD) criteria. Mild: FEV1 $>80 \%$ pred; moderate: FEV1 $50-80 \%$ pred; severe: FEV $130-50 \%$ pred; very severe: FEV1 $\leqslant 30 \%$ pred; BMl: body mass index; TRC: The Respiratory Centre.

very severe group had further urgent reviews in the next year, only $35 \%$ of them needed hospitalisation.

We suggest that the potentially patient-driven in-reach system of COPD care for selected patients in areas of high COPD burden highlighted within this letter could be particularly useful for severe patients who may otherwise place greatest strain on traditional models of COPD care. We therefore urge further well-designed research into this tool, which can assess its impact on hospital admission rates and quality of life.

\section{Iwuji, A. Rosich-Medina, N. Swaminathan, D. Baguley, C. Kirwin, K. Austin and R.J. Kurukulaaratchy \\ Dept of Respiratory Medicine, Southampton General Hospital, Southampton, UK.}

\section{STATEMENT OF INTEREST}

None declared. 


\section{REFERENCES}

1 The British Thoracic Society. Intermediate care - hospital-athome in chronic obstructive pulmonary disease. British Thoracic Society guidelines. Thorax 2007; 62: 200-210.

2 British Lung Foundation. Invisible lives - Chronic Obstructive Pulmonary Disease (COPD) - finding the missing millions. www.lunguk.org Date last updated: November 2007. Date last accessed: April 2008.
3 Global Initiative for Chronic Obstructive Lung Disease. The Global Strategy for the Diagnosis, Management and Prevention of Chronic Obstructive Pulmonary Disease. 2007 Update. www.goldcopd.org Date last updated: December 2007. Date last accessed: April 2008.

\section{Relationship between depression and exacerbations in COPD: a response}

\section{To the Editors:}

A well-conducted prospective study was published in a recent issue of the European Respiratory Journal (ERJ), which assessed the relationship between depressive symptoms, exacerbation frequency (as defined by the presence of two symptoms on 2 consecutive days), systemic inflammation, and social factors among 169 stable chronic obstructive pulmonary disease (COPD) patients [1]. QUINT et al. [1] found that patients with frequent exacerbations exhibited significantly more depressive symptoms than those with infrequent exacerbations.

The research of QUINT et al. [1] is unique because previous work [2] has mostly focused on cross-sectional links between depressive symptoms and admission for an exacerbation or mortality. As such, the prospective design used by QUINT et al. [1] is an important contribution to a field that still needs to be developed. However, the paper is limited by the fact that the authors did not assess anxiety symptoms or anxiety disorders. This is surprising given the fact that anxiety symptoms and anxiety disorders (i.e. clinical levels of anxiety) have been shown to be highly prevalent (up to 50\%) and highly comorbid with depression (14-26\%) in patients with COPD [3-5]. We, as well as others, have previously reported that anxiety disorders (e.g. generalised anxiety disorder, phobias) were even more prevalent than mood disorders (e.g. major depressive disorder, dysthymia) in patients with COPD (46-50\% versus $17-38 \%$, respectively) $[3,4]$. The assessment of anxiety in addition to depression is important from both a methodological and a clinical standpoint because of the comorbidity issue, and because it is unclear whether the results of the study by QUINT et al. [1] are due to depression or nonassessed anxiety. For example, QUINT et al. [1] postulate that patients with elevated depression scores may report greater levels of breathlessness or perceive symptom changes more readily. However, breathlessness and increased symptom awareness (or hypervigilance) are actually hallmarks of anxiety rather than depression [5]. QUINT et al. [1] quite rightly point out that the Center for Epidemiologic Studies Depression Scale questionnaire has benefits over other questionnaires as it has less overlap with anxiety symptoms. However, had QuINT et al. [1] used a questionnaire like the Hospital Anxiety and Depression Scale or a brief psychiatric interview like the Primary Care Evaluation of Mental Disorders, this issue of anxiety versus depression would have been negated.

While we agree with QUINT et al. [1] that depression and depressive symptoms are important factors in patients with COPD, and that greater efforts are needed to identify and treat patients with such disorders, we also believe that failing to assess anxiety in addition to depression means that their results should be interpreted with caution.

As highlighted by WAMBOLDT [6], future research needs to consider differential clinical phenotypes and outcomes of chronic obstructive pulmonary disease patients with depression and/or anxiety compared to patients without either psychiatric disorder. It is essential that studies continue to evaluate the impact of depression and anxiety on chronic obstructive pulmonary disease patients so that appropriate treatments can be developed.

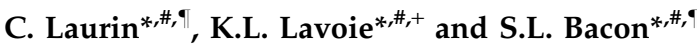

*Research Center, Hôpital du Sacré-Coeur de Montréal - a University of Montreal affiliated hospital, "Research Center, Montreal Heart Institute, "Dept of Exercise Science, Concordia University, and ${ }^{+}$Dept of Psychology, Université du Québec à Montréal (UQAM), Montreal, QC, Canada.

\section{STATEMENT OF INTEREST}

None declared.

\section{REFERENCES}

1 Quint JK, Baghai-Ravary R, Donaldson GC, Wedzicha JA. Relationship between depression and exacerbations in COPD. Eur Respir J 2008; 32: 53-60.

2 Almagro P, Barreiro B, Ochoa de Echaguen A, et al. Risk factors for hospital readmission in patients with chronic obstructive pulmonary disease. Respiration 2006; 73: 311-317

3 Kunik ME, Roundy K, Veazey C, et al. Surprisingly high prevalence of anxiety and depression in chronic breathing disorders. Chest 2005; 127: 1205-1211. 